\title{
Effects of I-Stepholidine on Forebrain Fos Expression: Comparison with Clozapine and Haloperidol
}

\author{
Yi-Qing Mo',2, Xi-Lu Jin ${ }^{2}$, You-Ting Chen ${ }^{3}$, Guo-Zhang Jin' and Wei-Xing Shi*, I,4 \\ 'Department of Pharmacology, State Key Laboratory of Drug Research, Shanghai Institute of Materia Medica, Shanghai Institutes of Biological \\ Sciences, Chinese Academy of Sciences, Shanghai, China; ${ }^{2}$ Department of Pharmacology, College of Pharmacy, Fudan University, Shanghai, China; \\ ${ }^{3}$ Department of Anatomy, Xuzhou Medical College, Xuzhou, China; ${ }^{4}$ Neuropsychopharmacological Research Unit, Department of Psychiatry, \\ Yale University School of Medicine, New Haven, CT, USA
}

\begin{abstract}
I-Stepholidine (SPD) is a tetrahydroprotoberberine alkaloid and a mixed dopamine DI agonist/D2 antagonist. Preliminary clinical trials suggest that SPD improves both positive and negative symptoms of schizophrenia without producing significant extrapyramidal side effects. Here, we report that SPD mimics the effect of the atypical antipsychotic drug clozapine, preferentially increasing Fos expression in corticolimbic areas. Thus, at $10 \mathrm{mg} / \mathrm{kg}$ (i.p.), SPD induced Fos expression in the medial prefrontal cortex (mPFC), nucleus accumbens (NAc), and lateral septal nucleus (LSN) without significantly affecting the dorsolateral striatum (DLSt). At higher doses (20-40 mg/kg), SPD also increased Fos expression in the DLSt. The increase, however, was less pronounced than the increase seen in the NAc. Within the NAc, SPD also induced more Fos expression in the shell than in the core. In all subcortical areas examined, the Fos expression induced by SPD was mimicked by the D2 antagonist sulpiride and reversed by the D2 agonist quinpirole, suggesting that the effect is due to blockade of D2-like receptors by SPD. In the mPFC, however, the effect was not mimicked by sulpride or reversed by quinpirole. It was also not mimicked by the DI agonist SKF38393 or SKF38393 plus sulpride, and not reversed by the DI antagonist SCH23390. These results suggest that, in the mPFC, SPD may induce Fos expression through a non-DA mechanism. Whether the mechanism involves an interaction of SPD with other neurotransmitters such as 5-HT and norepinephrine remains to be determined.

Neuropsychopharmacology (2005) 30, 26 I-267, advance online publication, I December 2004; doi: I 0. I038/sj.npp. I 300628
\end{abstract}

Keywords: stepholidine; c-fos; atypical antipsychotic; schizophrenia; negative symptoms

\section{INTRODUCTION}

l-Stepholidine (SPD) is a tetrahydroprotoberberine (THPB) alkaloid isolated from the Chinese herb Stephonia. Its biological activity was first examined in a rat hemiparkinsonian model, in which SPD produced an effect mimicked by dopamine (DA) D1 agonist SKF38393 and blocked by the D1 antagonist SCH23390 (Shi et al, 1984; Huang and Jin, 1992; Jin et al, 1992). Subsequent studies show that SPD binds directly to D1-like receptors $(\mathrm{Ki}=13 \mathrm{nM}, \mathrm{Xu}$ et al, 1989) and acts as a partial D1 agonist (Dong et al, 1997; Zou et al, 1997; see also reviews by Jin et al, 1987, 2002). Results also show that SPD binds to D2-like receptors as well $(\mathrm{Ki}=85 \mathrm{nM})$ and acts as a full D2 antagonist (Dong et al,

\footnotetext{
*Correspondence: Professor W-X Shi, Department of Psychiatry, Neuropsychopharmacological Research Unit, Yale University School of Medicine, 300 George Street, Room 8300C, New Haven, CT 065II, USA, Tel: + I 203785 4507, Fax: + I 203785 4510,

E-mail: wei-xing.shi@yale.edu

Received I June 2004; revised 5 October 2004; accepted 21 October 2004

Online publication: 29 October 2004 at http://www.acnp.org/citations/ NPPI02904040254/default.pdf
}

1997; Zou et al, 1997; see also reviews by Jin et al, 1987, 2002). To our knowledge, SPD is the first compound known to have mixed D1 agonist/D2 antagonist properties. Studies of the drug on non-DA receptors have been limited. Evidence suggests, however, that it differs from clozapine and haloperidol, exhibiting only low affinities for 5HT2 $(\mathrm{Ki}=300 \mathrm{nM}), \alpha 2(\mathrm{Ki}=400 \mathrm{nM})$ (Jin and Sun, 1995), and $\alpha 1$ receptors $(\mathrm{Ki}=2.5 \mu \mathrm{M})$ (Lei et al, 1999), and having no effect on glutamate NMDA receptor-mediated $\mathrm{Ca}^{2+}$ entry into cells (Gu, Yang, Jin, and Shi, unpublished observation).

As a partial D1 agonist and D2 antagonist, SPD may offer some advantages over traditional antipsychotic drugs, most of which are DA antagonists relatively selective for D2- $v s$ D1-like receptors. By blocking D2-like receptors, these drugs also remove the potent negative feedback mechanisms of DA neurons, resulting in an increase in DA release. With D2-like receptors blocked, this increase may lead to an unbalanced overstimulation of D1-like receptors. As a partial D1 agonist, SPD may prevent D1-like receptors from being overly activated and, at the same time, provide a submaximal stimulation of these receptors. Preliminary clinical trials suggest that SPD is an effective antipsychotic drug with a profile similar to that of clozapine (Wu et al, 
2003). When co-administered, SPD also enhances the therapeutic effects and reduces the tardive dyskinesia induced by typical antipsychotic drugs (Cai et al, 1988).

With the data available, however, it remains uncertain how exactly the mixed D1 agonist/D2 antagonist property may contribute to the atypical profile of SPD. To begin to address this issue, this study examined the role of D1- and D2-like receptors in effects of SPD on Fos expression in forebrain areas that are thought to be involved in the therapeutic and side effects of antipsychotic drugs (Deutch, 1994; Fibiger, 1994). We asked whether SPD, like clozapine, preferentially increases Fos expression in the medial prefrontal cortex (mPFC), the nucleus accumbens (NAc), and the lateral septal nucleus (LSN), and has less effect on the dorsolateral striatum (DLSt). Using specific DA agonists and antagonists, we also examined whether both D1- and D2-like receptors play a role in effects of SPD on Fos expression in these areas.

\section{MATERIALS AND METHODS}

\section{Drug Treatment}

Sprague-Dawley rats (Shanghai Animal Center, Chinese Academy of Sciences), weighing 250-300 g, were housed three per cage with free access to food and water and maintained in a 12-h light/dark cycle and temperaturecontrolled environment. To minimize Fos responses due to handling and injections, all animals were handled for 2$3 \mathrm{~min}$ and given an injection of saline per day for 4-7 days prior to drug administration. All experiments were in compliance with the Guide for the Care and Use of Laboratory Animals (National Research Council, 1996).

SPD (Shanghai Institute of Material Medical, Chinese Academy of Sciences) and clozapine (Shanghai Institute of Pharmaceutical Industry) were dissolved in $0.1 \mathrm{mM} \mathrm{H}_{2} \mathrm{SO}_{4}$ $(10 \mathrm{mg} / 150 \mu \mathrm{l})$ and then diluted with distilled water to $10 \mathrm{mg} / \mathrm{ml}$ with the $\mathrm{pH}$ adjusted to 5.0 using $0.1 \mathrm{mM} \mathrm{NaOH}$. Haloperidol ampoules were purchased from Shanghai Xudong Haipu Pharmaceutical Co. Ltd, China. SKF38393, sulpiride, SCH23390, and quinpirole (Sigma-RBI, CA, US) were dissolved in saline. All drugs were administered intraperitoneally (i.p.). Doses were $10-40 \mathrm{mg} / \mathrm{kg}$ for SPD, $10-20 \mathrm{mg} / \mathrm{kg}$ for clozapine, $0.3-1.0 \mathrm{mg} / \mathrm{kg}$ for haloperidol, $10 \mathrm{mg} / \mathrm{kg}$ for SKF38393, $0.5-1.5 \mathrm{mg} / \mathrm{kg}$ for SCH23390, $150 \mathrm{mg} / \mathrm{kg}$ for sulpiride, and $2 \mathrm{mg} / \mathrm{kg}$ for quinpirole. To control for the effect of SPD, additional animals were treated with vehicle $\left(2 \mathrm{ml} / \mathrm{kg}, 15 \mu \mathrm{M} \mathrm{H} \mathrm{H}_{2} \mathrm{SO}_{4}\right.$ with $\mathrm{pH}$ adjusted to 5.0 using $0.1 \mathrm{mM} \mathrm{NaOH}$ ).

At $2 \mathrm{~h}$ after the final injection, rats were deeply anesthetized with chloral hydrate $(500 \mathrm{mg} / \mathrm{kg})$ and transcardially perfused with $0.9 \%$ saline, followed by $300 \mathrm{ml}$ of $4 \%$ paraformaldehyde. The brains were post-fixed in the same fixative for $4-6 \mathrm{~h}$ and subsequently sunk in $30 \%$ sucrose (in $0.1 \mathrm{M} \mathrm{PB})$ overnight at $4{ }^{\circ} \mathrm{C}$. Serial coronal sections $(40 \mu \mathrm{m})$ were cut on a freezing microtome and stored at $-20^{\circ} \mathrm{C}$.

\section{Fos Immunohistochemistry}

Free floating sections were washed three times with $0.01 \mathrm{M}$ phosphate-buffered saline (PBS), permeabilized with $0.5 \%$ Triton $\mathrm{X}-100$, and incubated for $48 \mathrm{~h}$ at $4{ }^{\circ} \mathrm{C}$ with a primary rabbit polyclonal anti-Fos antibody directed against the amino-terminus of human c-Fos p62 (1:1000, Santa Cruz, $\mathrm{CA})$. The sections were then incubated with biotinylated secondary antibody (donkey anti rabbit IgG, 1:200, Vector, CA) followed by avidin-biotin-horseradish peroxidase complex (ABC, 1:200, Vector, CA). Brown cytosolic products were obtained by a reaction with $3,3^{\prime}$-diaminobenzidine $\left(\mathrm{DAB}, 0.50 \mathrm{mg} / \mathrm{ml}\right.$ ) and $0.005 \% \mathrm{H}_{2} \mathrm{O}_{2}$ for 5$10 \mathrm{~min}$. Sections were then mounted, dehydrated, and coverslipped. To control for the specificity of immunostaining, some sections were processed as above but without the primary or secondary antibody. No specific staining was observed under either condition.

\section{Quantification and Statistical Analysis}

Sections were examined under bright-field illumination using an Olympus microscope (IX71). Images were captured on a CoolSNAP-Procf digital camera (Media Cybenetics, US). The average number of Fos-like immunoreactive (FLI) nuclei was calculated from 3-4 sections through each of the sampled areas (Figure 1, dark squares). Automated counts of FLI nuclei were obtained within a $373 \times 373 \mu \mathrm{m}^{2}$ area, with the help of Metamorph system (5.0, Universal Imaging Corp, Downingtown, PA). A constant-background intensity was maintained across different sections and animals such that a Fos-positive nucleus was counted only if it reached a defined optical density threshold above background. FLI counts from each of the areas were averaged and the mean was used for subsequent statistical analysis. The 'atypical index' was calculated using a method similar to that described previously (Robertson et al, 1994). First, the numbers of FLI neurons in the NAc and DLSt were averaged in vehicle-

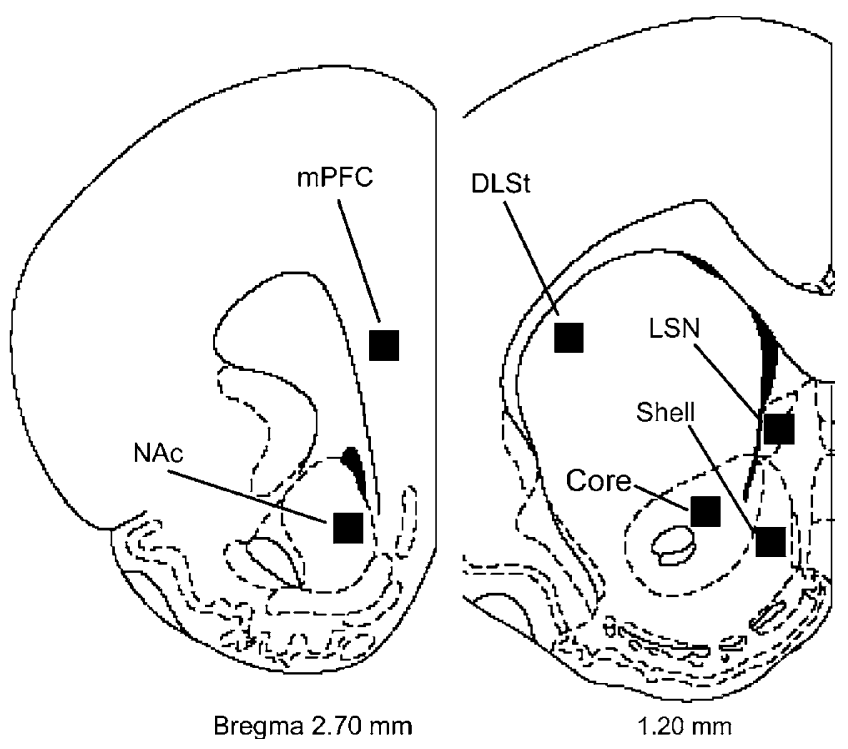

Figure I Schematic drawings, adapted from Paxinos and Watson (1998), showing areas (squares) chosen for quantitative analysis of Fos expression. FLI nuclei in the $\mathrm{mPFC}$ and NAc were counted at anteriorposterior $2.60-2.80 \mathrm{~mm}$, relative to bregma, and those in the LSN, DLSt, and the core and shell of the NAc were counted at anterior-posterior 2. $10-2.30 \mathrm{~mm}$, relative to bregma. 
treated rats. The average number of each area was then subtracted from the value of that area in each individual rat treated with either a drug or vehicle. An atypical index could then be obtained from every animal by subtracting the corrected value of the DLSt from that of the NAc. Statistical comparisons were performed using one-way ANOVA followed by a post hoc Newman-Keuls test or two-way ANOVA followed by a Tukey HSD test. Numerical results are presented as mean \pm SEM.

\section{RESULTS}

\section{Effects of SPD on Fos Expression}

To study the effect of SPD, four groups of rats were used. One was treated with the vehicle $\left(n=5,0.015 \mathrm{mM} \mathrm{H}_{2} \mathrm{SO}_{4}\right.$, $\mathrm{pH} 5.0,2 \mathrm{ml} / \mathrm{kg}$, see Materials and methods) and used as a control. The remaining three groups were injected (i.p.) with SPD at $10 \mathrm{mg} / \mathrm{kg} \quad(n=6), 20 \mathrm{mg} / \mathrm{kg} \quad(n=5)$, and $40 \mathrm{mg} / \mathrm{kg}(n=6)$, respectively. At $2 \mathrm{~h}$ after the injection, the animals were killed and the brains were processed for Fos immunostaining. The number of FLI nuclei was counted in four forebrain areas: the mPFC, NAc, LSN, and DLSt (Figure 1). Figure 2 shows representative photomicrographs of Fos immunostainings in the four areas after different doses of SPD. Figure 3 summarizes results from all rats. Compared to vehicle, all doses of SPD tested significantly increased FLI nuclei in the $\operatorname{mPFC}(\mathrm{F}(3,18)=49.94, p<0.001$; post hoc test $-10 \mathrm{mg}: p<0.05 ; 20 \mathrm{mg}: p<0.001 ; 40 \mathrm{mg}: p<0.001)$, NAc $(\mathrm{F}(3,18)=107.1, p<0.001 ; 10 \mathrm{mg}: p<0.001 ; 20 \mathrm{mg}$ : $p<0.001 ; 40 \mathrm{mg}: \quad p<0.001)$, and LSN $(\mathrm{F}(3,18)=40.9$, $p<0.001 ; \quad 10 \mathrm{mg}: \quad p<0.001$; $20 \mathrm{mg}: \quad p<0.001 ; \quad 40 \mathrm{mg}$ : $p<0.001$ ) (Figures 2 and 3). SPD also significantly increased
Fos expression in the DLSt $(\mathrm{F}(3,18)=57.36, p<0.001)$. Post hoc test showed, however, that the increase was significant at $20(p<0.001)$ and $40 \mathrm{mg} / \mathrm{kg}(p<0.001)$, and not at $10 \mathrm{mg} / \mathrm{kg}$ of SPD $(p=0.12)$.

For comparison, effects of clozapine and haloperidol were also examined in separate animals (Figure 3). Consistent with previous studies (eg Deutch and Moghaddam, 1992; Robertson and Fibiger, 1992; Robertson et al, 1994), clozapine $(20 \mathrm{mg} / \mathrm{kg}, \quad n=6)$ significantly increased FLI neurons in mPFC, NAc, and LSN, and produced no increase in the DLSt. At a lower dose $(10 \mathrm{mg} / \mathrm{kg}, n=5)$, it increased FLI nuclei in the NAc only (mPFC: $\mathrm{F}(2,13)=42.8, p<0.001$; post hoc test $-20 \mathrm{mg}: p<0.001$; $10 \mathrm{mg}: p=0.40$; NAc: $\mathrm{F}(2,13)=54.4, p<0.001 ; 20 \mathrm{mg}: p<0.001 ; 10 \mathrm{mg}: p<0.001$; LSN: $\mathrm{F}(2,13)=114.9, p<0.001 ; 20 \mathrm{mg}: p<0.001 ; 10 \mathrm{mg}$ : $p=0.8$; DLSt: $\mathrm{F}(2,13)=31.3, p<0.001 ; 20 \mathrm{mg}: p<0.001$; $10 \mathrm{mg}: p=0.65)$.

Unlike SPD and clozapine, haloperidol $(0.3 \mathrm{mg} / \mathrm{kg}, n=6$; $1 \mathrm{mg} / \mathrm{kg}, n=5$, Figure 3) slightly decreased Fos expression in the mPFC $(\mathrm{F}(2,13)=4.883, p=0.026$; post hoc test: $0.3 \mathrm{mg}: p=0.02 ; 1 \mathrm{mg}: p=0.015)$. In the same animals, haloperidol significantly increased FLI nuclei in the NAc $(\mathrm{F}(2,13)=78.8, p<0.001 ; 0.3 \mathrm{mg}: p<0.001 ; 1 \mathrm{mg}: p<0.001)$, LSN $(\mathrm{F}(2,13)=144.3, p<0.001 ; 0.3 \mathrm{mg}: p<0.001 ; 1 \mathrm{mg}$ : $p<0.001)$, and DLSt $(\mathrm{F}(2,13)=220.2, p<0.001 ; 0.3 \mathrm{mg}$ : $p<0.001 ; 1 \mathrm{mg}: p<0.001)$. Also, different from SPD and clozapine, haloperidol induced more FLI neurons in the DLSt than in the NAc, whereas SPD and clozapine preferentially increased Fos expression in the NAc. To illustrate this difference between drugs, the 'atypical index' was calculated for all animals including those in the vehicletreated group (see Materials and methods). As shown in Figure $4 \mathrm{a}$, atypical indexes of all three drugs were

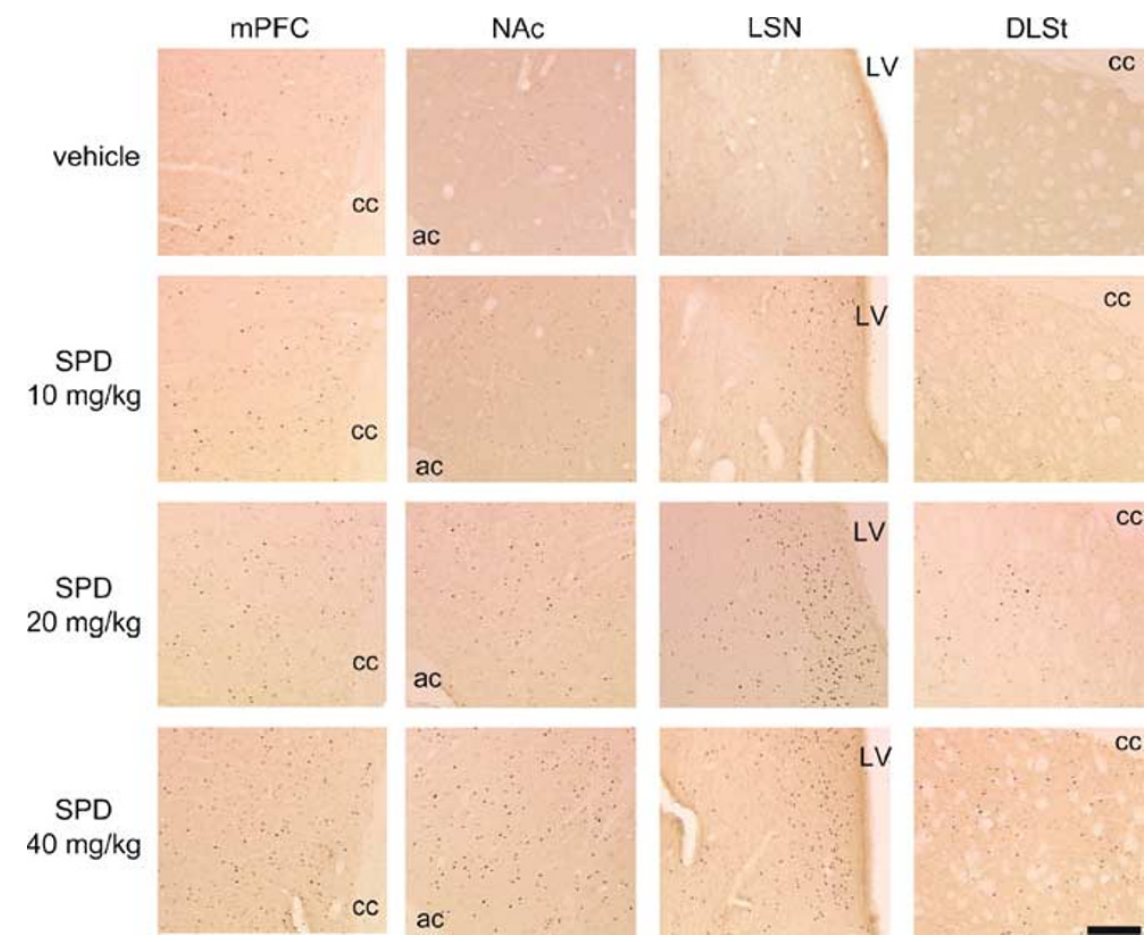

Figure 2 Representative photomicrographs showing effects of SPD on Fos expression in the mPFC, NAc, LSN, and DLSt. Scale bar $=200 \mu \mathrm{m}$. ac, anterior commissure; cc, corpus callosum; LV, lateral ventricle. 

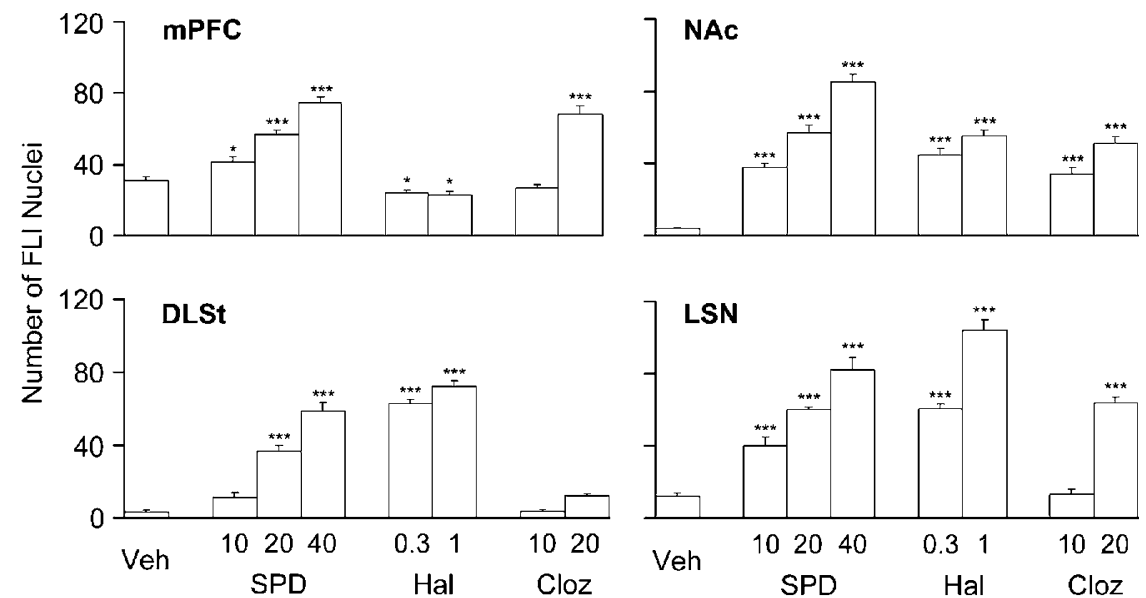

Figure 3 Summary bar graphs showing increases in the number of FLI nuclei in the mPFC, NAc, DLSt, and LSN induced by SPD (I0, 20, and 40 mg/kg), haloperidol (Hal, 0.3 and I mg/kg), and clozapine (Cloz, 10 and $20 \mathrm{mg} / \mathrm{kg}$ ), respectively. In this and the following figure, error bars are standard error of means. Note that, in the DLSt, the increase in Fos expression induced by $10 \mathrm{mg} / \mathrm{kg}$ of SPD was insignificant, and that haloperidol caused a small but significant decrease in Fos expression in the mPFC. $* p<0.05$, **** $p<0.00$ I compared to vehicle group.

significantly different from that of vehicle $(\mathrm{F}(7,36)=55.85$, $p<0.001$; post hoc test: SPD $10 \mathrm{mg}: p<0.001 ; 20 \mathrm{mg}$ : $p<0.001 ; 40 \mathrm{mg}: \quad p<0.001$; clozapine $10 \mathrm{mg}: \quad p<0.001$; $20 \mathrm{mg}: \quad p<0.001$; haloperidol $0.3 \mathrm{mg}: \quad p<0.001$; $1 \mathrm{mg}$ : $p<0.001)$. They were, however, positive for SPD and clozapine, and negative for haloperidol (Figure 4a), confirming that SPD and clozapine induced more Fos expression in the NAc than DLSt, whereas haloperidol preferentially increased FLI nuclei in the DLSt.

The NAc can be further divided into two subdivisions. The core of the NAc is more related to the extrapyramidal system, while the shell is more related to the limbic system. To examine whether SPD, like clozapine, preferentially increases Fos expression in the shell, two groups of rats were used, one treated with vehicle $(n=5)$ and the other with SPD $(30 \mathrm{mg} / \mathrm{kg}, n=5)$. As shown in Figure $4 \mathrm{~b}, \mathrm{SPD}$ increased Fos expression in both the shell and the core $(\mathrm{F}(1,16)=62.61, p<0.001$; post hoc test: shell: $p<0.001$; core: $p<0.01 v s$ vehicle). However, the number of FLI nuclei in the shell induced by SPD was significantly higher than that in the core $(\mathrm{F}(1,16)=20.0, p<0.001$, shell $v s$ core: $p<0.05$, Figure $4 \mathrm{~b}$ and $\mathrm{c})$.

\section{Role of D2-like Receptors in SPD-Induced c-fos Expression}

To test whether part of the effect of SPD is due to blockade of D2-like receptors, four groups of rats were treated with vehicle $(n=5)$, SPD $(40 \mathrm{mg} / \mathrm{kg}, n=6)$, the $\mathrm{D} 2$ agonist quinpirole $(2 \mathrm{mg} / \mathrm{kg}, \quad n=5)$, and SPD plus quinpirole $(n=6)$, respectively. As reported previously (Deutch and Duman, 1996; Alonso et al, 1999), quinpirole alone increased the number of FLI nuclei in the MPFC $(p<0.01$ $v s$ vehicle) and had no significant effect in all subcortical areas examined (NAc shell: $p=0.32$; NAc core: $p=0.80$; LSN: $p=0.29$; DLSt: $p=1.0$, Figure 5 upper chart). When co-administered with SPD, quinpirole significantly reduced the effect of SPD in all subcortical regions (NAc shell: $p<0.001$; NAc core: $p<0.001$; LSN: $p<0.001$; DLSt: $p<0.001$ vs SPD alone, Figure 5). In the mPFC, co-
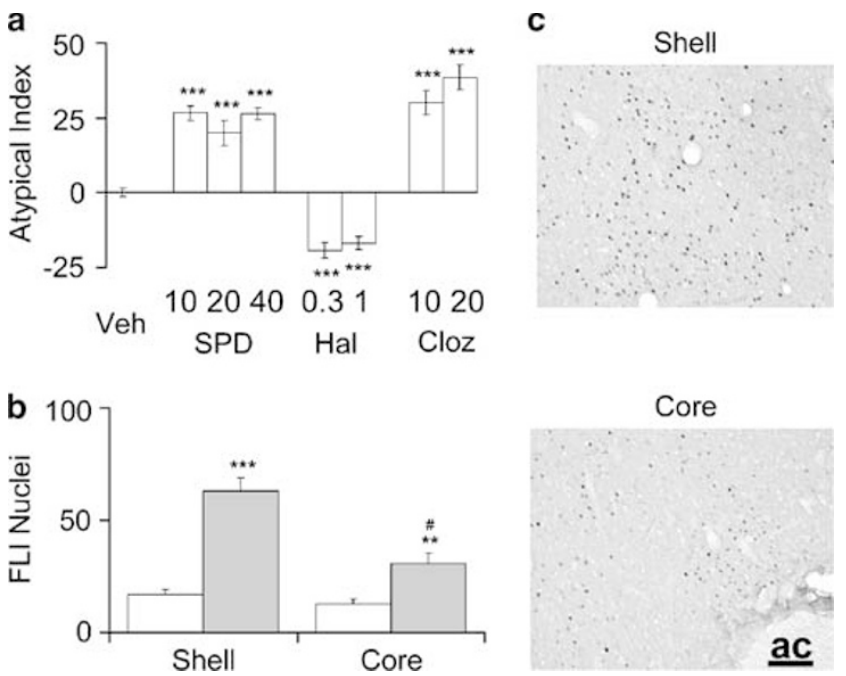

Figure 4 SPD preferentially increases Fos expression in limbic structures. (a) Bar graph showing the 'atypical indexes' of SPD (10,20,40 mg/kg), haloperidol $(0.3,1 \mathrm{mg} / \mathrm{kg})$, and clozapine $(10,20 \mathrm{mg} / \mathrm{kg})$. The indexes are positive for SPD and clozapine and negative for haloperidol. $* * * * 2<0.00$ I compared to vehicle. (b) Summary bar graph showing the difference in the number of FLI nuclei induced by SPD $(30 \mathrm{mg} / \mathrm{kg})$ in the shell and core. *** $p<0.0$ I, **** $p<0.00$ I compared to vehicle, ${ }^{*} p<0.05$ compared to the shell. (c) Representative photomicrographs showing that SPD induced more FLI nuclei in the shell than in the core of the NAc. Scale bar $=100 \mu \mathrm{m}$.

administration of quinpirole with SPD produced an increase in Fos expression greater than that induced by either drug alone $(p<0.01 v s$ quinpirole alone; $p<0.05$ vs SPD alone, Figure 5 upper chart).

To test whether blockade of D2-like receptors mimics the effect of SPD, the D2 antagonist sulpiride $(150 \mathrm{mg} / \mathrm{kg}, n=5)$ was administered. Like SPD ( $30 \mathrm{mg} / \mathrm{kg}, n=5)$, sulpiride increased the number of FLI neurons in subcortical structures (NAc shell: $p<0.001$; NAc core: $p<0.001$; LSN: $p<0.05$; DLSt: $p<0.001 v s$ vehicle, Figure 5 lower chart). Different from SPD, however, it produced no significant 


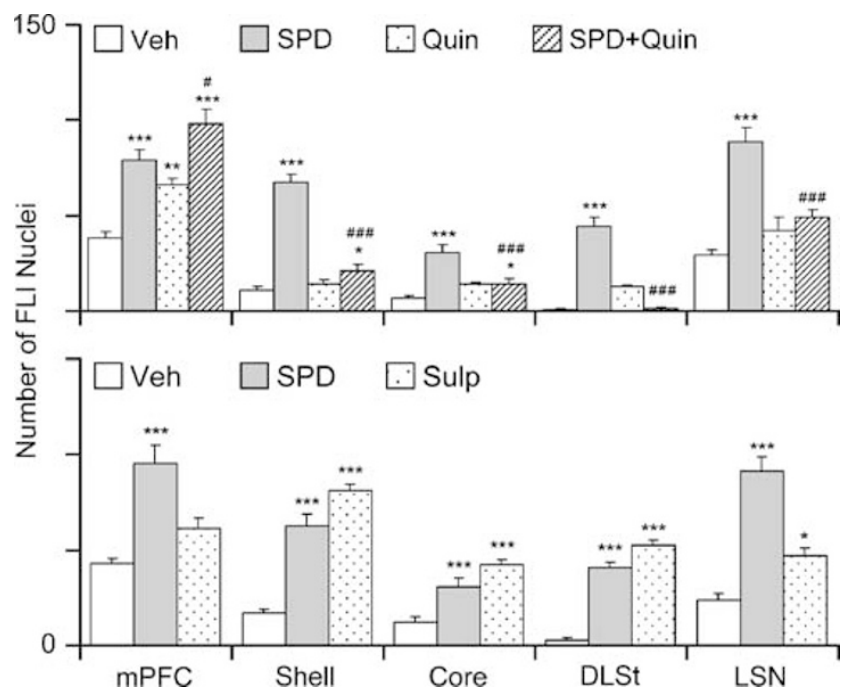

Figure 5 Summary bar graphs showing that in subcortical regions, but not in the mPFC, the increase in Fos expression induced by SPD $(40 \mathrm{mg} / \mathrm{kg})$ was reversed by quinpirole ( $2 \mathrm{mg} / \mathrm{kg}$, Quin, upper) and mimicked by sulpiride ( $150 \mathrm{mg} / \mathrm{kg}$, lower). Note that quinpirole alone caused a significant increase in FLI cells in the mPFC. $* p<0.05$, *** $p<0.0$ I, **** $p<0.00$ I compared to vehicle; ${ }^{\#}<<0.05,{ }^{\# \# \#} p<0.00$ I compared to SPD alone.

effect in the mPFC ( $p=0.10 v s$ vehicle; Figure 5 lower chart).

\section{Role of D1-like Receptors in SPD-Induced c-fos Expression}

To determine whether SPD acts in part by stimulating D1like receptors, effects of the D1 antagonist SCH23390 were examined. At $0.5 \mathrm{mg} / \mathrm{kg}(n=5), \mathrm{SCH} 23390$ alone had no effect in the mPFC ( $p=0.054 v s$ vehicle), NAc shell $(p=0.97$ $v s$ vehicle), NAc core $(p=0.67 v s$ vehicle), and DLSt ( $p=0.87 v s$ vehicle), and increased FLI nuclei in the LSN $(p<0.05 v s$ vehicle). At a higher dose $(1.5 \mathrm{mg} / \mathrm{kg}, n=5)$, SCH23390 also produced an increase in the mPFC $(p<0.05$ $v s$ vehicle, Figure 6 upper chart). When co-administered with SPD $(40 \mathrm{mg} / \mathrm{kg})$, both doses of SCH23390 failed to block the effect of SPD in the mPFC $(0.5 \mathrm{mg}: p=0.55$; $1.5 \mathrm{mg}: p=0.264 v s$ SPD alone), NAc shell (0.5 mg: $p=0.52$; $1.5 \mathrm{mg}: p=0.67$ vs SPD alone), NAc core $(0.5 \mathrm{mg}: p=0.99$; $1.5 \mathrm{mg}: p=0.88 v s$ SPD alone), and DLSt ( $0.5 \mathrm{mg}: p=0.29$; $1.5 \mathrm{mg}: p=0.41 v s$ SPD alone). In the LSN, co-administration of SPD with the high dose of SCH23390 induced more FLI nuclei than either drug alone $(p<0.01 v s$ SCH 23390 alone; $p<0.05 v s$ SPD alone; Figure 6 upper chart).

To test whether D1 activation mimics the effect of SPD, rats were treated with the D1 agonist SKF38393 $(10 \mathrm{mg} / \mathrm{kg}$, $n=5)$. Unlike SPD (30 mg/kg, $n=5)$, SKF38393 produced no significant effect in all regions examined (mPFC: $p=0.60$; NAc shell: $p=1.0$; NAc core: $p=0.66$; LSN: $p=0.76$; DLSt: $p=1.0$; Figure 6 lower chart). To determine further whether a combination of D1 activation and D2 blockade mimics the effect of SPD, rats were given both SKF38393 $(10 \mathrm{mg} / \mathrm{kg})$ and sulpiride $(150 \mathrm{mg} / \mathrm{kg}, n=5)$. The treatment increased FLI neurons in all subcortical areas examined (NAc shell: $p<0.001$; NAc core: $p<0.001$; LSN:

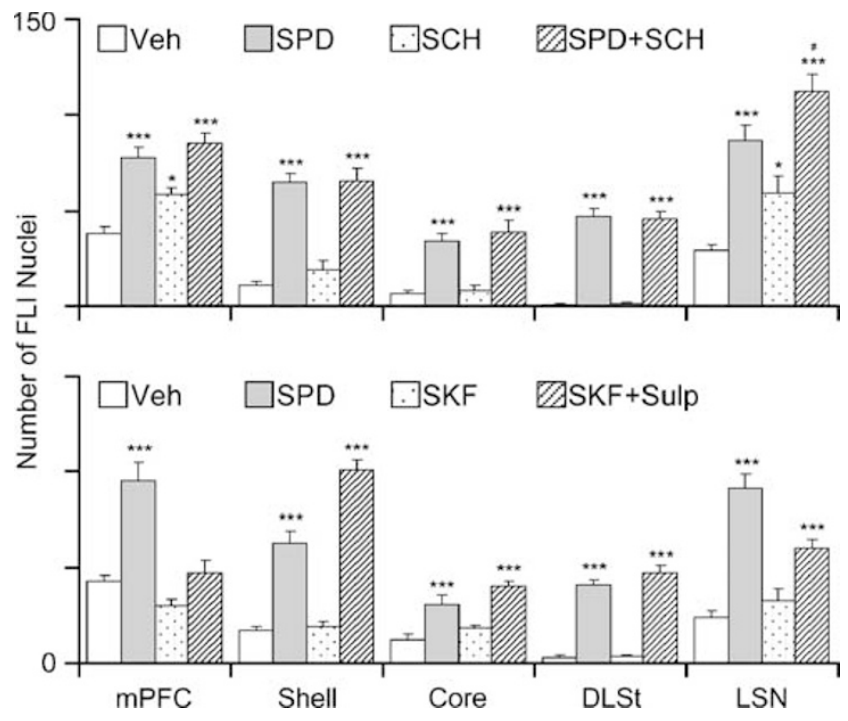

Figure 6 Summary bar graphs showing that effects of SPD $(40 \mathrm{mg} / \mathrm{kg})$ on Fos expression were not reversed by SCH23390 (I.5 mg/kg, SCH, upper). Effects of SPD $(30 \mathrm{mg} / \mathrm{kg})$ were also not mimicked by SKF38393 (10 mg/kg, SKF, lower). SKF38393 (I $0 \mathrm{mg} / \mathrm{kg})$ plus sulpiride $(150 \mathrm{mg} / \mathrm{kg})$ mimicked SPD's effects in subcortical areas but not in the mPFC (lower). ${ }^{*} p<0.05, * * * *<0.00$ I compared to vehicle; ${ }^{\#} p<0.05$ compared to SPD alone.

$p<0.001$; DLSt: $p<0.001 v s$ vehicle), but not in the mPFC $(p=0.63 v s$ vehicle, Figure 6 lower chart).

\section{DISCUSSION}

This study shows that SPD induces a pattern of Fos expression in forebrain areas similar to that induced by clozapine. Evidence further suggests that the effect of SPD in subcortical structures is mediated through the D2 blockade induced by the drug, whereas its effect in the mPFC is likely to involve more than D1 activation and/or D2 blockade.

The mPFC is believed to play a key role in the pathophysiology of negative symptoms and cognitive deficits in schizophrenia (see the review by Weinberger, 1988). All atypical antipsychotic drugs tested, including clozapine, increase Fos expression in the mPFC, whereas typical antipsychotic drugs such as haloperidol lack this effect. This finding has led to the suggestion that the increase in PFC Fos expression correlates the efficacy of an antipsychotic drug against negative symptoms (Robertson and Fibiger, 1992). This study confirmed that clozapine, but not haloperidol, increases Fos expression in the mPFC, and further showed that SPD mimicked the effect of clozapine. This finding is consistent with the clinical observation that SPD is effective in improving negative symptoms in schizophrenic patients (Wu et al, 2003).

SPD also dose-dependently increased Fos expression in the NAc, LSN, and DLSt. The effect in the NAc and LSN is shared by almost all clinical effective antipsychotic drugs tested (Robertson and Fibiger, 1992; Robertson et al, 1994) and may correspond to the ability of the drug to improve positive symptoms (Wu et al, 2003). Most antipsychotic drugs also increase Fos expression in the DLSt. The degree of increase, however, differs depending on the drug 
examined. Typical antipsychotic drugs usually induce more Fos expression in the DLSt than in the NAc, whereas atypical antipsychotic drugs preferentially affect the NAc, having either no effect or less effect in the DLSt (Dragunow et al, 1990; Miller, 1990; Robertson et al, 1994). Thus, a reduced effect in the DLSt may predict a low propensity of a drug to cause the extrapyramidal side effects. In this study, $\mathrm{SPD}$, at $10 \mathrm{mg} / \mathrm{kg}$, increased FLI neurons in the NAc without significantly affecting the DLSt. At higher doses, SPD also elevated Fos in the DLSt. The increase, however, was less pronounced compared to that in the NAc, giving rise to a positive 'atypical index' for SPD. Robertson and Fibiger (1992, 1996) evaluated 10 atypical and 8 typical antipsychotic drugs and found that the atypical index reliably differentiated the two classes of drugs, being positive for all atypical and negative for all typical antipsychotic drugs. The 'atypical' property of SPD is also reflected in its effect in the two subdivisions of the NAc. Functionally, the core of the NAc is more related to the extrapyramidal system, while the shell is more related to the limbic system (Brog et al, 1991; Deutch and Moghaddam, 1992). Like clozapine, SPD induced more FLI nuclei in the shell than in the core, whereas haloperidol preferentially increased FLI nuclei in the core. These results are consistent with the clinical finding that SPD at therapeutic doses has no significant extrapyramidal side effects (Wu et al, 2003).

In a previous study, however, low doses of SPD were shown to induce significant increases in Fos expression in the striatum (Guo et al, 1998). While the exact reason for the difference between studies is unclear, we noticed that in addition to a few darkly stained nuclei, SPD at $10 \mathrm{mg} / \mathrm{kg}$ induced many weak stainings in the DLSt. As they were only slightly above the background and so different from the darkly stained nuclei found in the same sections in the NAc and LSN, these weak stainings were not counted in the present study. Accurate counting of these stainings was in fact difficult using the computer-based imaging analysis system. In the study by Guo et al, these weak stainings may have been treated as FLI nuclei.

SPD is a mixed D1 agonist/D2 antagonist (see Introduction). Results of this study suggest that D2- but not D1-like receptors play a role in the Fos expression induced by SPD. Furthermore, the role of D2-like receptors seems to be restricted in subcortical regions. In these areas, the increase in Fos expression induced by SPD was reversed by the D2 agonist quinpirole and mimicked by the $\mathrm{D} 2$ antagonist sulpiride. The effect, however, was not blocked by the D1 antagonist SCH23390 or mimicked by the D1 agonist SKF38393. As discussed above, SPD preferentially increased Fos expression in the NAc. This preferential effect was also unaltered by $\mathrm{SCH} 23390$, suggesting that $\mathrm{D} 1$ activation is not critical to this 'atypical' property of SPD.

In the $\mathrm{mPFC}$, neither D1- nor D2-like receptors seem to be critical in the Fos expression induced by SPD. In this cortical area, the increase in Fos expression induced by SPD was not blocked by the D1 antagonist $\mathrm{SCH} 23390$ or the D2 agonist quinpirole. It was also not mimicked by the D1 agonist SKF38393 and/or the D2 antagonist sulpiride. The lack of a role of D1-like receptors was unexpected because there is evidence that D1 activation can lead to an increase in Fos expression in the mPFC (Glickstein et al, 2002; Diaz
Heijtz et al, 2004). One possibility is that both SPD and SKF38393 are partial D1 agonists and only a full D1 agonist can act through D1-like receptors to induce Fos expression in the mPFC. The finding that $\mathrm{SCH} 23390$ did not block the effect of SPD further supports the suggestion that D1-like receptors are unlikely to be involved in SPD-induced Fos expression.

As mentioned earlier, atypical antipsychotic drugs such as clozapine also increase Fos expression in the mPFC. The mechanism underlying the effect remains also elusive. A recent study suggests that adrenergic $\beta$ receptors may play a role in the effect of clozapine and olanzapine because propranolol, a $\beta$ antagonist, blocks the increase in Fos expression induced by both drugs (Ohashi et al, 2000). Preliminary results suggest that $\beta$ receptors may also play a partial role in the effect of SPD in the mPFC.

In conclusion, this study shows that SPD, like clozapine, preferentially increases Fos expression in the mPFC and limbic structures. This finding is consistent with the clinical observation that SPD improves both positive and negative symptoms and has no significant extrapyramidal side effects. Results further suggest that SPD-induced Fos expression in subcortical areas is due to blockade of D2like receptors, whereas its effect in the mPFC appears to involve more than D1 activation and/or D2 blockade. It is important to point out, however, that results of this study were all obtained after a single injection of SPD. To achieve significant levels of therapeutic effects, SPD, like other antipsychotic drugs, has to be administered chronically. Thus, to fully understand the role of D1- and D2-like receptors in the mechanism of action of SPD, studies using chronic treatment will be needed.

\section{ACKNOWLEDGEMENTS}

This work was supported by National Basic Research Program of China (973 Program) '2003CB515400', National Natural Science Fund '30230130' and '30271495'.

\section{REFERENCES}

Alonso R, Gnanadicom H, Frechin N, Fournier M, Le Fur G, Soubrie P (1999). Blockade of neurotensin receptors suppresses the dopamine D1/D2 synergism on immediate early gene expression in the rat brain. Eur J Neurosci 11: 967-974.

Brog JM, Deutch A, Zahm D (1991). Afferent projections to the nucleus accumbens core and shell in the rat. Soc Neurosci Abstr 41: $89-126$.

Cai N, Jin G, Zhang ZD (1988). A controlled study on the treatment of tardive dyskinesia using 1-stepholidine. Zhonghua Shen Jing Jing Shen Ke Za Zhi 21: 281-283.

Deutch AY (1994). Identification of the neural systems subserving the actions of clozapine: clues from immediate-early gene expression. J Clin Psychiatry 55(Suppl B): 37-42.

Deutch AY, Duman RS (1996). The effects of antipsychotic drugs on Fos protein expression in the prefrontal cortex: cellular localization and pharmacological characterization. Neuroscience 70: 377-389.

Deutch AY, Moghaddam B (1992). Regionally specific effects of atypical antipsychotic duugs on striatal Fos expression: the nucleus accumbens shell as a locus of antipsychotic action. Mol Cell Neurosci 3: 332-341. 
Diaz Heijtz R, Scott L, Forssberg H (2004). Alteration of dopamine D1 receptor-mediated motor inhibition and stimulation during development in rats is associated with distinct patterns of c-fos mRNA expression in the frontal-striatal circuitry. Eur J Neurosci 19: 945-956.

Dong ZJ, Guo X, Chen LJ, Han YF, Jin GZ (1997). Dual actions of (-)-stepholidine on the dopamine receptor-mediated adenylate cyclase activity in rat corpus striatum. Life Sci 61: 465-472.

Dragunow M, Robertson GS, Faull RL, Robertson HA, Jansen K (1990). D2 dopamine receptor antagonists induce fos and related proteins in rat striatal neurons. Neuroscience 37: 287-294.

Fibiger HC (1994). Neuroanatomical targets of neuroleptic drugs as revealed by Fos immunochemistry. J Clin Psychiatry 55(Suppl B): 33-36.

Glickstein SB, Hof PR, Schmauss C (2002). Mice lacking dopamine D2 and D3 receptors have spatial working memory deficits. J Neurosci 22: 5619-5629.

Guo X, Ding YM, Hu JY, Jin GZ (1998). Involvement of dopamine D1 and D2 receptors in Fos immunoreactivity induced by stepholidine in both intact and denervated striatum of lesioned rats. Life Sci 62: 2295-2302.

Huang K, Jin G (1992). The antagonistic effects of tetrahydroprotoberberines on dopamine receptors: electrophysiological studies. Sci China B 35: 688-696.

Jin G, Xu S, Yu L (1987). Tetrahydropalomatine and its analogues as new dopamine receptor antagonists. Trends Pharmacol Sci 8: 81-82.

Jin GZ, Huang KX, Sun BC (1992). Dual actions of (-)stepholidine on dopamine receptor subtypes after substantia nigra lesion. Neurochem Int 20(Suppl): 175S-178S.

Jin GZ, Sun BC (1995). Neuropharmacological effects of (-)stepholidine and its analogues on brain dopaminergic system. Adv Exp Med Biol 363: 27-28.

Jin GZ, Zhu ZT, Fu Y (2002). Stepholidine: a potential novel antipsychotic drug with dual D1 receptor agonist and D2 receptor antagonist actions. Trends Pharmacol Sci 23: 4-7.
Lei S, Orensanz LM, Mulvany MJ, Simonsen U (1999). Mechanisms involved in the vasorelaxant effect of (-)-stepholidine in rat mesenteric small arteries. Eur J Pharmacol 365: 193-204.

Miller JC (1990). Induction of c-fos mRNA expression in rat striatum by neuroleptic drugs. J Neurochem 54: 1453-1455.

National Research Council (1996). Guide for the Care and Use of Laboratory Animals. National Academy Press: Washington, DC.

Ohashi K, Hamamura T, Lee Y, Fujiwara Y, Suzuki H, Kuroda S (2000). Clozapine- and olanzapine-induced Fos expression in the rat medial prefrontal cortex is mediated by beta-adrenoceptors. Neuropsychopharmacology 23: 162-169.

Paxinos G, Watson C (1998). The Rat Brain in Stereotaxic Coordinates. Academic Press: Sydney.

Robertson GS, Fibiger HC (1992). Neuroleptics increase c-fos expression in the forebrain: contrasting effects of haloperidol and clozapine. Neuroscience 46: 315-328.

Robertson GS, Fibiger HC (1996). Effects of olanzapine on regional C-Fos expression in rat forebrain. Neuropsychopharmacology 14: 105-110.

Robertson GS, Matsumura H, Fibiger HC (1994). Induction patterns of Fos-like immunoreactivity in the forebrain as predictors of atypical antipsychotic activity. J Pharmacol Exp Ther 271: 1058-1066.

Shi WX, Chen Y, Jin GZ (1984). Effect of $l$-stepholidine on rotational behavior in rats. Acta Pharmacol Sin 5: 222-225.

Weinberger DR (1988). Schizophrenia and the frontal lobe. Trends Neurosci 11: 367-370.

Wu DC, Xing XZ, Wang WA, H X, Wang HH, Wang XY, Cong Z, Jin GZ (2003). A double blind comparison trial of L-stepholidine and perphenazine in treatment of schizophrenia. Chin J New Drugs Clin 22: 155-160.

Xu SX, Yu LP, Han YR, Chen Y, Jin GZ (1989). Effects of tetrahydroprotoberberines on dopamine receptor subtypes in brain. Zhongguo Yao Li Xue Bao 10: 104-110.

Zou LL, Liu J, Jin GZ (1997). Involvement of receptor reserve in D1 agonistic action of (-)-stepholidine in lesioned rats. Biochem Pharmacol 54: 233-240. 